\title{
Preliminary Study Influence of Wear on High Temperature Oxidation Performance of U71Mn Rail Steel
}

\author{
Yanjun $\mathrm{Xi}^{*}$, Xianzhe Li, Yongjun Liu, Ying Liu, Xiaoyan Guan and Haiqing Jiang \\ School of Materials and Chemical Engineering, Zhongyuan University of Technology, Zhengzhou 450007, P.R.China
}

${ }^{*}$ Corresponding author

\begin{abstract}
The objective of this study is to preliminary explore the effect of wear on high temperature oxidation performance of U71Mn rail steel. The specimens was tested at $500 \mathrm{~N}$ on abrasion testing machine, and then performed at high temperature in the furnace. The surface and cross section was investigated by SEM with EDS. Oxide phase was analysized by XRD. The results showed that deep scratches on wear samples cause the oxide film to fall off seriously, so that the weight gains at high temperature is smaller than that of the non-wear samples. The oxide is rough, unstable and exfoliated easily. The oxidation rate of U71Mn after wear is higher than that without wear. Therefore, the high temperature caused by frequent friction plays an important role in the service life of high-speed trains.
\end{abstract} steel

Keywords-wear; high temperature oxidation; U71Mn; rail

\section{INTRODUCTION}

Since 1980s, high speed trains have appeared in France and Germany, promoting the high speed of the main trunk lines in Europe. Then high speed railway construction is rapidly rising ${ }^{[1-3]}$.

The existing research shows that the friction heat is one of the most important factors that cause damage of the rail when high speed train passes ${ }^{[4-9]}$. Wheel/ rail temperature rise will aggravate wheel rail abrasion, and even make a phase change of rail material, resulting in cracks on the rail surface, causing damage and spalling ${ }^{[10-11]}$.

During the operation of high speed railway, friction heat is produced by the relative sliding of wheel and rail ${ }^{[12-16]}$. The friction heat is concentrated in the contact area of the wheel and rail, which makes the temperature of the contact area rise rapidly. Vo K D, Naeimi $M$ and Shebani A have studied the friction temperature rise of wheel/ rail through numerical simulation. It is considered that the maximum temperature of the wheel /tread contact area is about $900^{\circ} \mathrm{C}^{[17-20]}$.

According to the literature on wheel rail friction temperature rise, the wheel /rail friction temperature raises at least $800^{\circ} \mathrm{C}$. Although the high temperature duration of the material is very short, the material will undergo rapid oxidation at a high temperature under sufficient oxygen conditions. The train operation has a strong impact on the rail, and the friction may cause great damage to the oxide or the matrix, which directly affects the service life of the rail. This problem has not been reported yet. Therefore, this paper studies the process of forming high temperature oxide after friction, which has important guiding significance for understanding the failure evolution of rail.

\section{EXPERIMENTAL DETAILS}

In this study, samples are cut into $15 \mathrm{~mm} \times 15 \mathrm{~mm} \times 15 \mathrm{~mm}$ from original U71Mn steel using wire cutting machine. Grinding with sand paper, polishing and cleaning are carried out.

Wear tests are performed on abrasion testing machine. The force of $500 \mathrm{~N}$ is adopted to simulate the contact stress between the wheel and rail. The wear tests elongated for $30 \mathrm{~S}$ with $500 \mathrm{~N}$ or $1000 \mathrm{~N}$. the sample is taken down and weighed. Then the sample is loaded for other 30 s test. The total time is 300 s.

High temperature oxidation tests are carried out with wear and non-wear samples. The corrosion morphology and the phase structure of corrosion products were characterized by optical microscopy, scanning electron microscopy with energy dispersive and XRD.

\section{RESULTS}

\section{A. Test Results of High Temperature Oxidation}

Figure I is the macro morphology of $\mathrm{U} 71 \mathrm{Mn}$ at $800^{\circ} \mathrm{C}$ after 5 h. Gray brittle oxide layer is formed on the surface, which may be $\mathrm{Fe}_{3} \mathrm{O}_{4}$. The oxide layer is almost completely peeled off from the lower oxide. When we just touch it, it falls off in the form of slag. The oxide of the lower layer can clearly show brownish red, which may be $\mathrm{Fe}_{2} \mathrm{O}_{3}$.XRD also proved the existance of $\mathrm{Fe}_{3} \mathrm{O}_{4}$ and $\mathrm{Fe}_{2} \mathrm{O}_{3}$, as shown in Figure II.

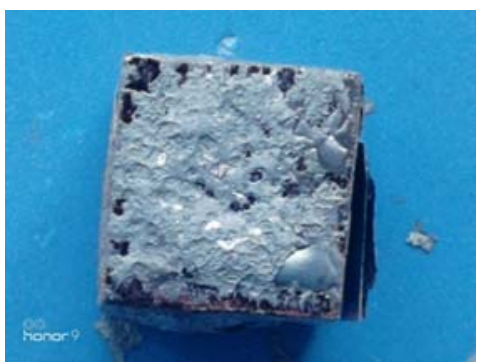

FIGURE I. MACRO MORPHOLOGY OF U71MN AT $800^{\circ} \mathrm{C}$ AFTER 5H 


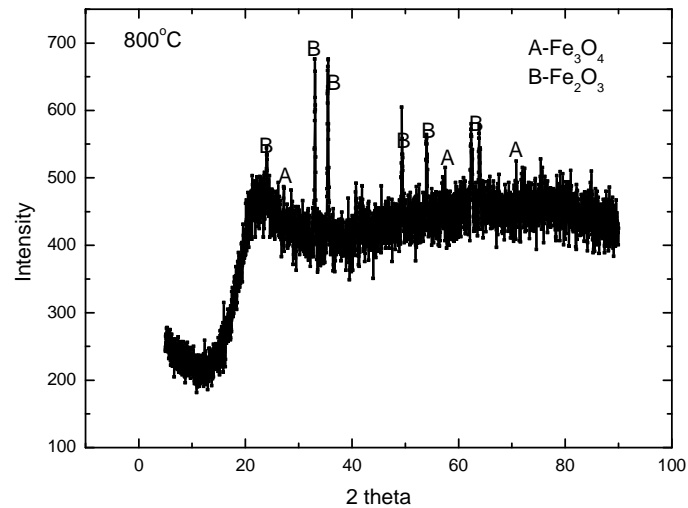

FIGURE II. XRD OF U71MN AT $800^{\circ} \mathrm{C}$ AFTER 5H

The cross section SEM observation of $\mathrm{U} 71 \mathrm{Mn}$ at $800^{\circ} \mathrm{C}$ for $5 \mathrm{~h}$ is carried out. As shown in Figure III, the total thickness of the oxide layer is about $120 \mu \mathrm{m}$. The bonding force between the outer layer and the subsurface layer is very poor. There are a large number of voids and holes, which is one of the reasons for peeling off of outer layer. EDS analysis indicate that outer layer mainly contains $\mathrm{Fe}$ and $\mathrm{O}$, with a partial $\mathrm{C}$ and a small number of $\mathrm{Mn}$. The component of outer layer is 27.44Fe-58.33O-13.98C-0.26Mn, as shown in Figure IV. The outer layer may be $\mathrm{Fe}_{3} \mathrm{O}_{4}$. The XRD also proves the existence of $\mathrm{Fe}_{3} \mathrm{O}_{4}$

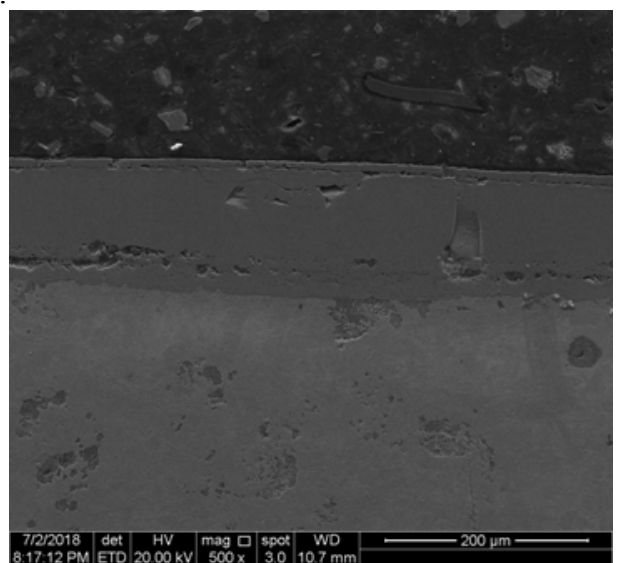

FIGURE III. CROSS-SECTIONAL SEM OF U71MN AT $800^{\circ} \mathrm{C}$ AFTER 5H

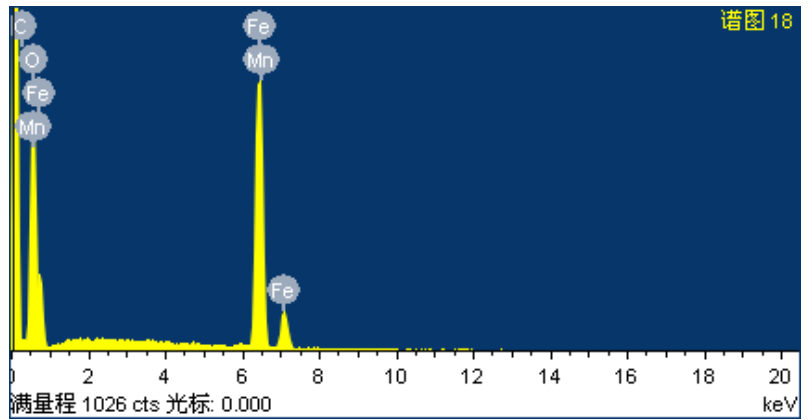

FIGURE IV. EDX OF OUTERMOST LAYER OF U71MN AT $800^{\circ} \mathrm{C}$ AFTER $5 \mathrm{H}$
Figure $\mathrm{V}$ is the macro morphology of wear samples after $500 \mathrm{~N}$ for $300 \mathrm{~s}$ at $800^{\circ} \mathrm{C}$ for $5 \mathrm{~h}$. The surface produces black oxide, mainly $\mathrm{Fe}_{3} \mathrm{O}_{4}$. The color is uneven, the doping of some brick red and gray white, which is mainly $\mathrm{Fe}_{2} \mathrm{O}_{3}$ and $\mathrm{FeO}$. Because these oxides grow faster, the particles are larger, the surface is rough, and the oxidation layer is uneven, brittle. The oxide is bulge, so some areas have already fallen off.

Friction causes plastic deformation and cracks on the surface of U71Mn rail along the longitudinal direction. The oxygen in the air is adsorbed and enriched at the tip of the crack. The high temperature oxide reduces the binding force of the grain boundary atoms and reduces the binding energy of the atomic bond at the crack front. The crack surface energy can be reduced and the crack growth is accelerated. At the same time, the oxide will quickly fall off with the crack.

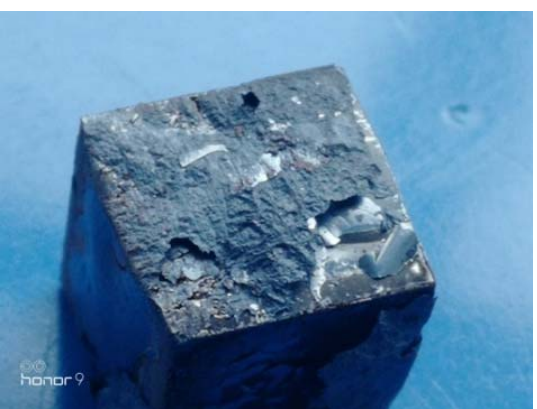

FIGURE V. MACRO MORPHOLOGY OF WEAR SAMPLES AFTER $500 \mathrm{~N}$ FOR $300 \mathrm{~S}$ AT $800^{\circ} \mathrm{C}$ FOR $5 \mathrm{H}$

\section{CONCLUSIONS}

(1) Serious oxidation of U71Mn occurred in a short period of high temperature.

(2) The deep scratches on wear samples cause the oxide film to fall off seriously, so that the weight gain of oxidation is smaller than that of the non-wear samples.

(3)After wear, the oxidation rate of U71Mn is higher than that without wear. Therefore, the high temperature caused by frequent friction plays an important role in the service life of high-speed trains.

\section{ACKNOWLEDGEMENT}

This research was financially supported by the Natural Science Foundation Project of Henan Province (182300410231).

\section{REFERENCES}

[1] R. Vickerman, Can high-speed rail have a transformative effect on the economy, Transport Policy. 62 (2018)31-37.

[2] J. I. Castillo-Manzano, M. Castro-Nuńo, L. López-Valpuesta, High speed rail: fast tracking tourism in the EU, Annals of Tourism Research. In press(2018).

[3] Y. H. Zhang, Q. Y. Zhou, L. Bao, Comparative study on rail performance of high speed railway home and abroad, China Railway Science. 36(2015)20-26.

[4] J. M. Xu, P. Wang, Y. Gao, Geometry evolution of rail weld irregularity and the effect on wheel-rail dynamic interaction in heavy haul railways, Engineering Failure Analysis. 81(2017)31-34. 
[5] M. Hiensch, and M. Steenbergen, Rolling contact fatigue on premium rail grades: damage function development from field date, Wear. 394-395(2018)187-194.

[6] Y. B. Huang, L .B. Shi, X. J. Zhao, On the formation and damage mechanism of rolling contact fatigue surface cracks of wheel/rail under the dry condition, Wear.400-401(2018)62-73.

[7] L. Ma, L. B. Shi, J. Guo, On the wear and damage characteristics of rail material under low temperature environment condition, Wear. 394-395(2018)149-158.

[8] U. Spangenberg, R.D. Fröhling, and P. S. Els, The effect of rolling contact mitigation measures on wheel wear and rail fatigue, Wear. 398-399(2018)56-68.

[9] D. I. Fletchern, Numerical simulation of near surface rail cracks subject to thermal contact stress, Wear. 314(2014)96-103.

[10] H.H. Ding, Z.K. Fu, W. J. Wangn, J. Guo, Q.Y. Liu, M.H. Zhu, Investigation on the effect of rotational speed on rolling wear and damage behaviors of wheel/rail materials, Wear. 330-331 (2015) 563-570.

[11] G. Trummer, K. Six, C. Marte, P. Dietmaier, and C. Sommitsch, An approximate model to predict near-surface ratcheting of rails under high traction coefficients, Wear. 314, 28-35(2014)

[12] M. Naeimi, S. G. Li, Z. L. Li, Thermomechanical analysis of the wheel-rail contact using a coupled modelling procedure, Tribology International. 117 (2018)250-260.

[13] W. J. Jiang, C. Liu, C. G. He, Investigation on impact wear and damage mechanism of railway rail weld joint and rail materials, Wear. 376-377(2017)1938-1946.

[14] H. Z. Ji, H. Su, C. F. Yang, Friction Heat Induced Phase Transformation and Spalling Mechanism of Train Wheel Steel, Journal of Iron and Steel Research. 17(2005)55-59.

[15] W.S. Farren, G.I. Taylor, The heat developed plastic extension of metals, Proceedings of the Royal Society A. 107(1925)422-451.

[16] M.Ertz, K.Knothe, A comparison of analytical and numerical methods for the calculation of temperature in wheel/rail contact, Wear. 253(2002)498-508

[17] K. D. Vo, A. K. Tieu, H. T. Zhu, The influence of high temperature due to high adhesion condition on rail damage, Wear. 330-331(2015)571-580.

[18] M. Naeimi, S. G. Li, Z. L. Li, Thermomechanical analysis of the wheel-rail contact using a coupled modelling procedure, Tribology International. 117(2018)250-260.

[19] A. Shebani, S. Iwnicki, Prediction of wheel and rail wear under different contact conditions using artificial neural networks, Wear. In press(2018).

[20] Y. F. Pei. Y. S. Jin, S. Z. Wen, Temperature rise due to slip between wheel and rail, China Railway Science(in China). 16(1995)81-86. 